\title{
CRISIS DE SEGURIDAD NACIONAL: \\ origen y consecuencias en los sexenios de Felipe Calderón, Enrique Peña Nieto y el inicio de la 4T
}

NATIONAL SECURITY CRISIS:

origin and consequences in the six-year terms of Felipe Calderón, Enrique Peña Nieto and the beginning of 4T

\begin{abstract}
Abraham Betanzo - abrahamjesusmendozabetanzo@gmail.com Universidad Nacional Autónoma de México (UNAM) - México
\end{abstract}

\section{RESUMEN}

Brevemente el presente ensayo se basó en el periodo desdemocratizador de seguridad vívido a partir del sexenio de Felipe Calderón, Enrique Peña Nieto y finaliza con los dos primeros años de gobierno de la Cuarta Transformación. El ascenso de los cárteles del narcotráfico y la vulneración del Estado mexicano ante la cantidad de homicidios, feminicidios, secuestros y extorsiones principalmente. Se analizó de acuerdo con la variable de seguridad la poca efectividad que representan las instituciones de seguridad púbica locales y el cómo se formuló una estrategia para combatir la inseguridad en el país, siendo una estrategia reformada sexenio con sexenio y con resultados poco o nada favorables.

Palabras clave / descriptores: México. Seguridad Nacional. Crisis.

\begin{abstract}
Briefly, this essay was based on the lived de-democratizing period of security from the six-year term of Felipe Calderón, Enrique Peña Nieto and ends with the first two years of government of the Fourth Transformation. The rise of drug cartels and the violation of the Mexican State in the face of the number of homicides, feminicides, kidnappings and extortion mainly. The lack of effectiveness represented by local public security institutions was analyzed according to the security variable and how a strategy was formulated to combat insecurity in the country, a reformed strategy being six-year with six-year and with little or no favorable results.
\end{abstract}

Keywords: Mexico. National security. Crisis.

\section{INTRODUCCIÓN}

Brevemente el presente ensayo se basó en el periodo desdemocratizador de seguridad vívido a partir del sexenio de Felipe Calderón, Enrique Peña Nieto y finaliza con los dos primeros años de gobierno de la Cuarta Transformación. El ascenso de los cárteles del narcotráfico y la vulneración del Estado mexicano ante la cantidad de homicidios, feminicidios, secuestros y extorsiones principalmente.

Se analizó de acuerdo con la variable de seguridad la poca efectividad que representan las instituciones de seguridad púbica locales y el cómo se formuló una estrategia para combatir la inseguridad en el país, siendo una estrategia reformada sexenio con sexenio y con resultados poco o nada favorables. 


\section{APARTADO TEÓRICO}

Charles Tilly -politólogo, sociólogo e historiador estadunidense- mencionaba que "ninguna democracia puede funcionar si el Estado carece de la capacidad para supervisar la toma de decisiones democráticas y poner en práctica sus resultados" (Tilly, 2007: 15, citado por Bizberg 2015).

En lo que concierne al origen de la problematización de seguridad en México no se debe dejar de lado el aspecto internacional, "El presidente de los Estados Unidos (EE. UU.) Richard Nixon (1969-1972) inició la Guerra contra las Drogas (War on Drugs) en 1971. Nixon argumentó que los narcotraficantes van a traficar drogas siempre y cuando exista un mercado. Además, se enfocó más en la demanda invirtió recursos financieros para combatir la adicción a las drogas en los EE. UU" (Bagley, 2013; Cuellar, 2008, citado por Rosen y Zepeda 2015). Es por ello por lo que creó la DEA -Administración de Drogas y Narcóticos- que pasó a ser el principal organismo que combatiría el tráfico de drogas, tanto nacional como internacionalmente, a partir de los setenta la guerra contra las drogas en Estados Unidos pasaría a formar parte de la agenda y esencia de la seguridad. Posterior al gobierno de Nixon, Ronald Reagan -sucesor de Nixon- no dejó de lado el combate de producción, cultivación y venta de drogas en los Estados Unidos; él se basó en un sistema de combate al tráfico de drogas por medio de la política exterior, es decir, mediante acuerdos con otros gobiernos con la mayor distribución de drogas hacia Estados Unidos, ejemplos de estos países son Bolivia, Perú y Colombia.

"Expertos como Bruce Bagley han indicado que si las personas en los EE. UU no fueran adictas, los gobiernos de América Latina no tendrían problemas con el narcotráfico y el crimen organizado" (Rosen y Zepeda, 2015, p. 155).

Entonces la administración de Reagan movilizaría sus propuestas con los entonces presidentes de Bolivia y Perú, en el primero, el presidente Reagan invertiría en un programa llamado "Operación Alto Horno" para eliminar la cosecha y producción en la provincia llamada Chapare, en el segundo, en el combate a la transportación que se hacía desde Perú hasta los laboratorios colombianos, este programa se denominó "Alta Dignidad"; "el resultado de estos programas fue que las rutas de producción de cocaína se trasladaron a Colombia, ya que en el año 2000, Colombia cultivó casi el 90\% de la coca en el mundo" (Bagley, 2012, citado por Rosen y Zepeda 2015).

A pesar de los innumerables logros por el gobierno estadunidense a cargo de Reagan en materia de seguridad y combate a las drogas en América Latina, provocó que los mercados de Bolivia y Perú se trasladaran hacia otros horizontes como Colombia, no fue diferente con el presidente Clinton al continuar con la política exterior ya desarrollada por Reagan, pues uno de sus primeros compromisos fue poner en marcha el "Plan Colombia" que básicamente se enfocaba en un acuerdo para que ambos países erradicaran la producción y el tráfico de estupefacientes hacia los Estados Unidos y en Colombia, lo que solo causó una mayor producción en el país. El problema no solamente fue la cantidad monetaria invertida, sino también que las fuerzas armadas de Colombia tomaron un mayor control de la creación y distribución de las drogas; por otro lado, siendo una víctima del Plan Colombia un país como México, al desmantelar y movilizar los cárteles de la región andina se traspasaron a territorio mexicano. "El ballon effect se da cuando un cuando un gobierno decide combatir la producción y tráfico de drogas en un país o región; lo que da como resultado que el cultivo, la producción y el tráfico de las drogas cambien a otro país o región contigua" (Carpenter, 2003, 84; citado por Rosen y Zepeda 2015).

Una vez ya establecido el problema en México con el auge del crimen organizado y el tráfico de drogas, queda claro que a raíz de la guerra contra las drogas iniciada en Estados Unidos fue el detonante para que México viviera una problemática de inseguridad y hasta de salud nacional. 
Para empezar, México experimentó su periodo democratizador a partir del año 2000 con la llegada al poder con Vicente Fox Quesada (2000-2006) por el Partido Acción Nacional (PAN), luego de que el partido hegemónico del PRI gobernara alrededor de 70 años y mantuviera una mayoría en el Congreso parecería que el país lograría vivir una de sus épocas más reconfortantes, plurales y transitorias democráticas; en este sentido la seguridad es una de las variables que debe contemplarse para el funcionamiento de una democracia, pues ella forma parte esencial del bienestar cotidiano que se vive socialmente.

Sin embargo, de acuerdo con Rosen \& Zepeda (2015) "en el sexenio de Fox (2000-2006) también surgieron nuevas organizaciones criminales violentas, como los Zetas y la Familia Michoacana, que además de dedicarse al tráfico de drogas, recurrían a otras actividades como el secuestro y la extorsión" (p. 158). El énfasis que menciona Rosen y Zepeda se refiere a que desde antes de que la alternancia política panista llegara al poder, los grupos criminales eran financiados y subordinados por el poder político del PRI, en los años 70 estados del país como Sinaloa, Durango, Chihuahua, Michoacán y Guerrero eran centro de cultivo de marihuana y amapola. La seguridad en el país empezaría a debilitarse y verse vulnerable a raíz del auge de cárteles criminales, así como también de organizaciones locales y estatales que atemorizarían a la población, por ende, a finales del siglo XIX e inicios del siglo XX México empezaría a vivir una situación desdemocratizadora a partir del crecimiento de los diferentes grupos criminales en determinados y diversos estados de la República.

De ahí que en los últimos años de Fox al mando del ejecutivo los niveles de violencia incrementaron y los altos niveles de inseguridad causado por el narcotráfico pasó a ser una de las cuestiones principales que el Estado mexicano enfrentaría en posteriores gobiernos.

La presidencia de Fox se caracterizó por el mantenimiento de las instituciones que el viejo régimen del PRI otorgó, las opciones de crear, reformar y/o desmantelar dichas instituciones no fue prioridad en el gobierno foxista; al contrario, intervenir de manera directa en las elecciones próximas de 2006 atacando al opositor y candidato por el PRD, Andrés Manuel López Obrador para así favorecer a su compañero de partido, Felipe Calderón Hinojosa, también candidato presidencial en 2006.

Ahora bien, no hay evidencia que compruebe que las elecciones de 2006 hayan sido ilegítimas ya que la victoria panista con su candidato Felipe Calderón rebasó por apenas $0.5 \%$ el proceso electoral. Para que se pueda afirmar que hubo irregularidades electorales debe haber un margen del $25 \%$ de casillas alrededor del país que así lo confirmen de acuerdo con el Instituto Nacional Electoral (INE).

\section{APARTADO CONTEXTUAL / HISTÓRICO}

Felipe Calderón Hinojosa, presidente de México del año 2006-2012, fue uno de los iniciadores levantando en armas a los comandos policiales y del ejército para combatir y eliminar el narcotráfico en México, a finales del año 2006 -mes en que toma posesión como presidente constitucional de México- dio el banderazo para el "Operativo conjunto Michoacán" operativo con el cual se desplegaron a más de 5000 elementos del ejército, marina y de la policía en el estado de Michoacán para contrarrestar el crimen organizado en dicha entidad, cabe mencionar que no solo sería a nivel estatal, sino nacional.

Un primer aspecto para señalar el por qué el inicio contra el narcotráfico en México es que los niveles de violencia se incrementaron -como ya se mencionó anteriormente a partir de los últimos años del gobierno foxista-, las dependencias gubernamentales como la policía local en el país pasaba a ser parte del complejo problema, pues la impunidad y la corrupción eran característica 
de estas entidades de seguridad pública; por ello, la primer acción de gobierno federal que hizo Calderón fue encomendar tareas de orden público al ejército, lanzar al espacio público a los elementos de las fuerzas armadas para mantener la paz y estabilidad social. La militarización del país fue la entrada abanderada del presidente Calderón, buscar la legitimidad presidencial por medio de la seguridad fue una idea bien planteada, pero mal aplicada; además el gobierno de Calderón no enfocó su atención a la mal aplicada estrategia de militarización en Colombia.

"México recibió la asistencia de los EE. UU. en la lucha contra el narcotráfico y ambos países implementaron una iniciativa de cooperación conocida como el "Plan México" qué más tarde cambió el nombre a Iniciativa Mérida (IM)" (Lendman, 2008, citado por Rosen y Zepeda 2015).

Dicha iniciativa fue el 13 de marzo de 2007 en la ciudad de Mérida Yucatán en una prestigiosa visita del presidente Bush, este contrato en materia de seguridad fue el principal peldaño formal de política exterior para que los Estados Unidos estuvieran también al tanto de lo que sucedía en México con los cárteles de la droga y su actividad de traspasar droga -entre otro tipo de negocios- al país vecino del norte. La principal técnica aplicada era atrapar, encarcelar y/o asesinar a las cabecillas al mando de los cárteles de la droga en el país; por medio del poder legislativo en México logró la creación y expansionismo de las fuerzas militares, el 05 de mayo de 2007 se publicó el "DECRETO por el que se crea el cuerpo especial del ejército y Fuerza Aérea denominado Cuerpo de Fuerzas de Apoyo Federal" (DOF, 2005).

Es así como se incorporan nuevos elementos de las fuerzas armadas al apoyo de las autoridades civiles, ya sea en el nivel federal, estatal, municipal y local; a dichas autoridades militares se les otorgó plena confianza y herramientas -armas, mandos, equipamientos, entre otros aspectos- para cumplir con la orden de erradicar a las organizaciones criminales del país.

El poder otorgado a las variadas instituciones del ejército formó parte de la época desdemocratizadora del país, la capacidad estatal en materia de seguridad se vería debilitada y amenazada debido a la operación ineficaz de las autoridades jerárquicamente establecidas para así crear organismos heterogéneos de fuerzas armadas.

En relación con el narcotráfico vivido en el país, se explica en primera instancia que los homicidios, los secuestros, las extorsiones, los feminicidios y la trata de personas se elevaron en números a partir de la guerra contra la droga en México; los cárteles en México empezaron a dividirse en organizaciones criminales estatales y locales porque chocarían por un conflicto de intereses y de confrontaciones que a su paso dejarían miles de muertes. La escisiones provocadas por el declive del nombrado "Pacto por la Federación" donde los cárteles de México llegarían a determinados acuerdos para repartirse el territorio mexicano fueron preponderantes en fechas posteriores a las de 2006-2007; durante 2008 y 2010: el cártel de la Familia Arellano Félix (Cartel de Tijuana) sufrió una división por parte de su lugarteniente Teodoro García Simental, que se rumoreaba que trabajaba ahora con el Cártel de Sinaloa al mando de el "Chapo" Guzmán y el Mayo Zambada; el Cártel de Juárez al mando de Amado Carrillo "El Señor de los Cielos" donde igual hubo enfrentamientos con el Cártel de Sinaloa.

Otro de los rompimientos en los cárteles fue con la salida de los hermanos Beltrán-Leyva del Cártel de Sinaloa, comenzando a trabajar en el centro, así como al suroeste del país. Del lado del noreste de México, el cártel del Golfo sufrió una escisión complicada, pues el grupo que se desprendería de éste, serían denominados Los Zetas -grupo criminal formado por GAFES del ejército mexicano, así como también de elementos criminales guatemaltecos- y por último en el estado de Michoacán, la división de la familia michoacana creándose el grupo criminal llamados los Caballeros Templarios.

No cabe duda de que el país estaría atravesando ser el epicentro de nuevos grupos criminales, tanto nacionales como locales; aparte de que la corrupción por parte de la policía federal al mando del entonces Secretario de Seguridad Pública, Genaro García Luna sería cuestionado ya que se considera que se protegía y apoyaba el cártel más poderoso de México y del mundo, el cártel 
de Sinaloa. Existen diversas interpretaciones acerca de la fragmentación de los cárteles, pero cierto es que, de ser seis organizaciones criminales en México, pasarían a multiplicarse hasta llegar alrededor de 14 -sin contar organizaciones locales-. (Anexo 1).

Durante la administración calderonista, de acuerdo con cifras del INEGI hubo más de 121, 683 muertes violentas -aunado a ello las denominadas narcoejecuciones-. La expuesta violación de derechos humanos por parte de los grupos criminales y del ejército fue uno de los puntos detonantes para que la militarización en el país siguiera; los daños colaterales en el país se dejaron entrever, por solo mencionar un caso, los estudiantes baleados al salir del tecnológico de Monterrey, Monterrey por elementos del ejército mexicano, donde estos afirman que pertenecían a un grupo criminal, la muerte y amenaza a periodistas mexicanos, como el exilio de la periodista Anabel Hernández. La guerra contra las drogas solo dio una muestra de lo que es el "efecto cucaracha", es decir, "la teoría del "desplazamiento del crimen" argumenta que con determinadas estrategias anticrimen el delito simplemente se relocalizará y no se eliminará si no se atacan sus causas radicales. Tal desplazamiento puede ser de lugar, de tiempo, de objetivo, de estrategia, o de tipo de crimen" (Morales, 2011, pp.20-21) (Anexo 2).

\section{DESARROLLO}

Una vez concluido el periodo en la presidencia con Calderón, el PRI regresaría al poder de la mano de Enrique Peña Nieto -presidente constitucional 2012-2018-, donde "se comprometió a cambiar la estrategia de la guerra contra el narcotráfico, concentrándose menos en la captura de los capos y más en enfrentar los problemas subyacentes, tales como la corrupción y la fragilidad de las instituciones de seguridad" (Rosen y Zepeda, 2016, p. 59).

Un primer ejemplo de las medidas tomadas por Peña Nieto, de acuerdo con Arroyo (2018) "De manera paralela, se hizo un ajuste en la estructura orgánica y a partir del 2 de enero de 2013, a doce años de su creación, desapareció la Secretaría de Seguridad Pública (SSP) para dar paso al Consejo Nacional de Seguridad Pública (CNSP), dependiente de la Secretaría de Gobernación (Segob), que en conjunto se encargarían de formular y ejecutar las políticas, programas y acciones para garantizar la seguridad de los mexicanos" (p. 204).

Algo más que añadir es que el gobierno peñista se tomaría en serio de enfocarse en reformar las instituciones, ya que de ellas se originaba el problema de la impunidad y corrupción. Peña Nieto no solamente pondría a funcionar a dos instituciones administrativas-logísticas, por otro lado, la creación de una policía militarizada -autoridades de carácter civil, pero con entrenamiento y preparación militar- fue aprobada y "oficialmente, el 16 de septiembre de 2013, coincidiendo con el desfile de las fuerzas armadas, inició sus operaciones la Gendarmería Nacional, integrada por cinco mil efectivos" (Arroyo, 2018, p. 205).

Este grupo policiaco no sería lo suficientemente robusto para cumplir con una estrategia de seguridad como la que demandaba el combate al narcotráfico, el tema de la cantidad de recursos fue otro problema, pues año tras año en la administración de Peña Nieto de 2012 a 2018 pasó de $\$ 2,595,000,000$ a 300,000,000 el Programa Nacional de Prevención del Delito, siendo el 2017 en que no se le destinó recurso alguno.

Luego, en el año 2014 dos acontecimientos relevantes sería el detonante que expondría que una vez más la militarización en el país, la propuesta de organismos de mando único policial y/o de seguridad y la total confianza en las fuerzas armadas son un peligro para la democratización en el país; la matanza de Tlatlaya -civiles son acribillados por el ejército- y la desaparición de los 43 normalistas de Ayotzinapa -grupo de jóvenes manifestantes en camino son detenidos por elementos 
policiales municipales y son entregados al crimen organizado- son solo dos casos que expone las represalias que se viven a causa de la guerra contra las drogas.

De acuerdo con Serrano (2019) "En septiembre de 2018, en su sexto y último informe de gobierno, el expresidente Enrique Peña Nieto anunció una victoria parcial sobre la captura y neutralización de 110 de los 122 objetivos prioritarios que identificó su gobierno como los delincuentes de mayor peligro para México" (p. 213).

La estrategia al final de Peña Nieto fue en esencia la misma que la de Calderón, reformar unas instituciones, ejecutar a altos mandos de los cárteles y crear divisiones nuevas con el ejército. "Las 125395 carpetas de investigación iniciadas por el delito de homicidio durante la administración de Peña Nieto rebasan las 102327 carpetas acumuladas durante la administración de Calderón" (Serrano, 2019, p. 212).

Por último, México cambiaría de rumbo político para la elección presidencial en el año de 2018, debido a la incapacidad principalmente en área de seguridad pública, el hartazgo social fue imperante y decisivo a votar por la denominada izquierda mexicana, Movimiento de Regeneración Nacional (MORENA), a cargo de su fundador Andrés Manuel López Obrador.

Obrador, con más de 30,000,000 de votos electorales viviría las consecuencias resentidas del sexenio de Peña: la crisis de seguridad.

Inicialmente con Alfonso Durazo -candidato a Secretario de Seguridad por MORENAmencionó que los homicidios se reducirían en una escala de $30-50 \%$ en un periodo a tres años, debido a la realidad que se presentaba retiró lo dicho en sus promesas y acuerdos durante la campaña. Es sustancial dejar claro que el discurso durante campaña es uno, pero al momento de gobernar la realidad choca con la utopía vendida por el discurso.

El entonces confirmado Secretario de Seguridad y Protección Ciudadana, Alfonso Durazo informó al Senado que los elementos militares regresarían a los cuarteles, cuando los planes de la renovada administración de profesionalizar a los policías y pacificar al país tuvieran frutos, hasta el año 2024. Aunado a lo anterior, el día 11 de mayo de 2020 se publicó en el Diario Oficial de la Federación el "ACUERDO por el que se dispone de la Fuerza Armada permanente para llevar a cabo tareas de seguridad pública de manera extraordinaria, regulada, fiscalizada, subordinada y complementaria" (DOF, 2020). Lo dicho hasta aquí supone que la militarización en el país seguirá avanzando, pero con diferentes caminos, estrategias y resultados, sobre todo.

La reestructuración de las dependencias gubernamentales para crear la ahora Secretaria de Seguridad y Protección Ciudadana (SSPC) fue separar a la Comisión Nacional de Seguridad, las entidades de prevención del delito, el servicio de protección federal, entre otro tipo de unidades administrativas de seguridad fueron reacomodadas y separadas; el trabajo en conjunto como un mando único desaparecería. Las secretarias como la SEGOB, ahora la SSPC y la autónoma Fiscalía General de la República (FGR) verían sus funciones específicas y limitadas, pues ahora, la creación de corporaciones para combatir la inseguridad quedaría extintas y se dejaría en manos de las fuerzas armadas, ahora, con un plan más amplio otorgado desde el poder ejecutivo. Hay que mencionar que con una mayoría en el Congreso de la Unión y una legitimidad bastante fuerte, las acciones del presidente López Obrador no parecería incomodar a la ciudadanía, aun así los cárteles en México seguirían cobrando fuerza, donde hasta este momento uno de los más poderosos ha sido el Cártel Jalisco Nueva Generación, creado a partir de rupturas en las organizaciones criminales.

"Con la decisión de la Suprema Corte de Justicia sobre la inconstitucionalidad de la Ley de Seguridad Interior en ciernes, la propuesta de la Guardia Nacional fue entonces retomada en el Plan Nacional de Paz y Seguridad 2018-2024 anunciado por AMLO, el 14 de noviembre de 2018" (Serrano, 2019, p. 219).

La Guardia Nacional pasaría a ser parte de los pilares en materia de seguridad, un organismo mezclado con la extinta policía federal, elementos del ejército mexicano, marina, fuerza aérea y 
aquellos ciudadanos voluntarios que quieran formar parte de este organismo desconcentrado con tareas civiles. De modo que, no solo sería brindar más tareas de orden público a las fuerzas armadas, sino que seguir con la estrategia -fallida- de que el ejército es la solución para combatir el narcotráfico es cuestionable; además la creación de programas sociales que ayuden a jóvenes a desarrollar sus capacidades de educación formó parte del discurso del presidente para evitar que el narcotráfico llegara por ellos.

Otro rasgo se basa en los derechos humanos, "Marcela Villalobos representante de Amnistía Internacional, llamó la atención al hecho de que la capacitación en materia de derechos humanos para miles de soldados de Sedena no había frenado que los militares cometan graves violaciones de derechos humanos" (Serrano, 2019, p. 221). Lo cual significa que las instituciones de seguridad y de armada en México no son $100 \%$ confiables y garantes de la protección, pues a raíz de la guerra contra las drogas también fueron cooptadas las organizaciones de seguridad, donde se ha llegado a reflejar el debilitamiento del Estado de derecho, un ejemplo de ello son los casos que han existido ante la Corte Interamericana de los Derechos Humanos; donde se ha denunciado que integrantes del ejército y de la marina han violado estos principios. Cuando se aprobó el organismo de la Guardia Nacional tuvo una amplia mayoría de aprobación tanto por los gobiernos estatales, diputados y senadores del país.

\section{CONSIDERACIONES FINALES}

México ha transitado por la vía de la militarización desde hace ya 14 años, la guerra contra las drogas en México fue el detonante de una cosecha de explosivos que se venía gestado desde finales del siglo XX. La colaboración que se creó entre el gobierno de México y de Estados Unidos para combatir las drogas no ha disminuido, pues al eliminar -atrapando o ejecutando- a los altos mandos de los cárteles mexicanos queda comprobado que no se eliminará la organización, las autoridades a cargo de contrarrestar la violencia en el país han dejado de ser efectivas y en consideración de los gobiernos antes mencionados, innecesarias.

El ejército mexicano pasó a ser la principal arma para poner un orden en la seguridad pública, consideraron que servían más en las calles que en los cuárteles; lo cierto es que el ejército ha sido expuesto por la enorme contribución de corrupción al sistema político mexicano. Todo lo planteado hasta ahora confirma que México ha pasado por un periodo de desdemocratización, donde la demanda por parte de la sociedad civil para contar con instituciones de seguridad más confiables y de cercanas ha disminuido, así orillándolos a que se defiendan organizados en grupos de la sociedad civil con armas para proteger sus tierras; aunado a lo anterior las organizaciones criminales como el cártel de Sinaloa ha sido cercana al pueblo del norte, principalmente en lo que se denomina "el triángulo dorado" ya que acciones sociales como el alumbrado público, llegada de internet ala sierra, centros religiosos y educativos, entre otro tipo de obras públicas que le competen al Estado lo cumplen las organizaciones criminales con un solo objetivo: respaldo y apoyo. La negociación con el crimen organizado con Calderón, la ignorancia a la delincuencia y asesinatos en masa con Peña Nieto y el proceso sólido de militarización con López Obrador; la ausencia del Estado fue notorio, pues en la escala internacional estamos dentro de los 150 países más violentos.

Se concluye que México es víctima de un periodo desdemocratizador debido a la ineficacia de la seguridad en México, concentración de tareas públicas a determinados organismos del ejército y la incapacidad de llevar el discurso a la práctica.

\section{ANEXOS}




\section{Anexo 1}

\begin{tabular}{|c|c|c|}
\hline 2006 & 2007-2009 & 2010-2012 \\
\hline \multirow{2}{*}{ Cártel de Sinaloa } & Cártel de Sinaloa & \multirow{2}{*}{$\begin{array}{l}\text { Cártel de Sinaloa } \\
\text { Cártel de los Beltrán Leyva } \\
\text { Cártel Independiente de Acapulco } \\
\text { Cártel de La Barbie }\end{array}$} \\
\hline & Cártel de los Beltrán Leyva & \\
\hline \multirow{2}{*}{ Cártel de Juárez } & \multirow{2}{*}{ Cártel de Juárez } & Cártel de Juárez \\
\hline & & La Línea \\
\hline \multirow{2}{*}{ Cártel de Tijuana } & Cártel de Tijuana & Cártel de Tijuana \\
\hline & Facción de E I Teo & Facción de El Teo \\
\hline \multirow{2}{*}{ Cártel del Golfo } & Cártel del Golfo & Cártel del Golfo \\
\hline & Los Zetas & Los Zetas \\
\hline \multirow{2}{*}{ La Familia Michoacana } & \multirow{2}{*}{ La Familla Michoacana } & La Famillia Michoacana \\
\hline & & Los Caballeros Templarios \\
\hline \multirow{2}{*}{ Cártel del Milenio } & \multirow{2}{*}{ Cártel del Milenio } & Jalisco Nueva Generación \\
\hline & & La Resistenda \\
\hline
\end{tabular}

Fuente: Bagley (2012: 241).

\section{Anexo 2}

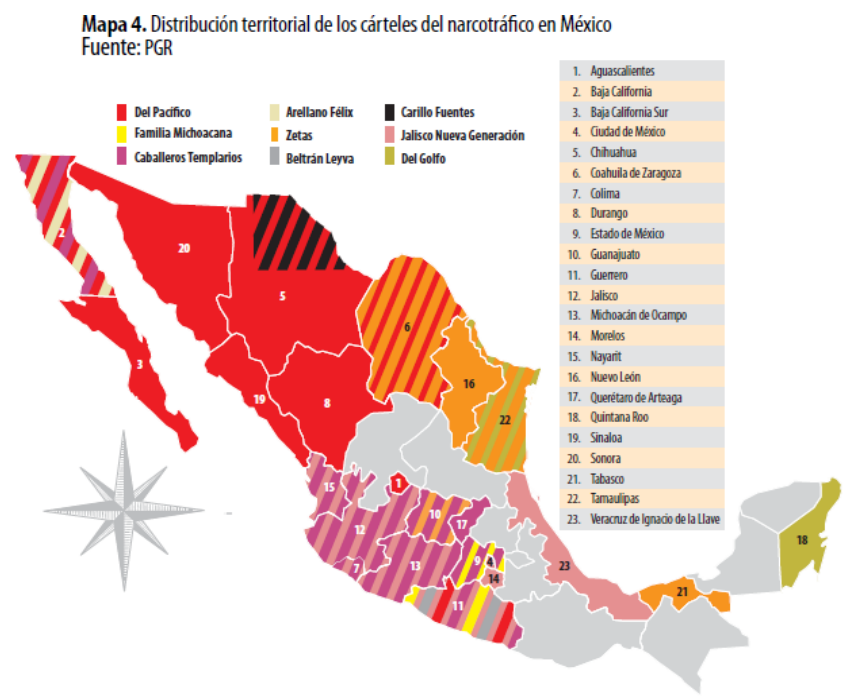

\section{REFERENCIAS}

Arroyo, E. (2018). Enrique Peña Nieto y la crisis de seguridad que hereda. 2021, de ITESO, Universidad Jesuita de Guadalajara Sitio web: https://analisisplural.iteso.mx/2018/10/10/enriqu e-pena-nieto-y-la-crisis-de-seguridad-quehereda/

Bizberg, Ilán. (2015). "México: una transición fallida." Desacatos, 48, mayo-agosto 2015, pp. 122-139.

Diario Oficial de la Federación. (2007). DECRETO por el que se crea el Cuerpo Especial del Ejército y Fuerza Aérea denominado Cuerpo de Fuerzas de Apoyo Federal. 2021, de Secretaria de Gobernación Sitio web: http://dof.gob.mx/nota detalle.php?codigo $=498$ $\underline{\text { 7036\&fecha }=09 / 05 / 2007}$

Diario Oficial de la Federación. (2020). ACUERDO por el que se dispone de la Fuerza Armada permanente para llevar a cabo tareas de seguridad pública de manera extraordinaria, regulada, fiscalizada, subordinada y complementaria. 2021, de Secretaria de Gobernación Sitio web:

https://www.dof.gob.mx/nota_detalle.php?codig $\mathrm{o}=5593105 \&$ fecha $=11 / 05 / 2020$

D. Rose, J. \& Zepeda, R.. (2016). Una década de narcoviolencia en México: 2006-2016. 2021, de Biblioteca Daniel Colosio Villegas Sitio web: https://repositorio.colmex.mx/concern/book cha 
pters/zw12z6074?f\%5Bdate_created_sim\%5D $\% 5 \mathrm{~B} \% 5 \mathrm{D}=2016 \& \mathrm{f} \% 5 \mathrm{Btemporary}$ coverage_si $\mathrm{m} \% 5 \mathrm{D} \% 5 \mathrm{~B} \% 5 \mathrm{D}=$ Siglo $+\mathrm{XXI} \&$ locale $=\mathrm{es}$

Escalante, F. (2011). Homicidios 2008-2009 La mиеrte tiene permiso. (2014, 30 marzo). Nexos. https://www.nexos.com.mx/?p=14089

Escalante Gonzalbo, F. (2013). Paisaje antes de la batalla. Notas sobre el contexto de la guerra contra las drogas en México. Revista Mexicana de Ciencias Políticas y Sociales, 58(218), 73104. https://doi.org/10.1016/s01851918(13)72290-6

Guerrero, E. (2016). La inseguridad 2013-2015. (2016, 3 enero). Nexos.

https://www.nexos.com.mx/?p=27269\#ftn1

Hope, A. ¿Seguirá la violencia? (2019, 19 febrero). Nexos. https://www.nexos.com.mx/?p=40946

Lajous, A. (2013). El periodismo que el narco nos dejó. (2013, 1 julio). Nexos. https://www.nexos.com.mx/?p=15386\#ftn6

Morales Oyarvide, César (2011). LA GUERRA CONTRA EL NARCOTRÁFICO EN MÉXICO. DEBILIDAD DEL ESTADO, ORDEN LOCAL Y FRACASO DE UNA ESTRATEGIA. Aposta.
Revista de Ciencias Sociales, (50),1-35. [fecha de Consulta 22 de enero de 2021]. ISSN: Disponible en:

https://www.redalyc.org/articulo.oa?id=4959/49 5950246005

República, P. (2020). 100 compromisos del presidente Andrés Manuel López Obrador, al 1 de septiembre de 2020. gob.mx.

Rosen, J. D., \& Zepeda Martínez, R. (2015). La guerra contra el narcotráfico en México: una guerra perdida The War on Drugs in Mexico: A Lost War. Revista Reflexiones, 94(1), 153-168. https://doi.org/10.15517/rr.v94i1.20889

Serrano Carreto, Mónica del Carmen (2019). La estrategia de seguridad de AMLO. ¿De la pacificación a la militarización? IUS. Revista del Instituto de Ciencias Jurídicas de Puebla A.C., 13(44),207-227. [fecha de Consulta 23 de enero de 2021]. ISSN: Disponible en: https://www.redalyc.org/articulo.oa?id=2932/29 3261227009

Solis Delgadillo, J. M. \& Morriconi Bezerra, M. (2018). Atlas de la Violencia en América Latina. San Luis Potosí, México: UASLP. 